\title{
Probing of the Voltammetric Features of Graphite Electrodes Modified with Mercaptoundecanoic Acid Stabilized Gold Nanoparticles
}

\author{
Rubin Gulaboski,,,,,$+ \S$ Mariana Chirea, ${ }^{\dagger}$ Carlos M. Pereira, ${ }^{*, \dagger}$ M. Natália D. S. Cordeiro, \\ Renata B. Costa, ${ }^{\dagger}$ and A. Fernando Silva ${ }^{\dagger}$ \\ CIQ-UP LA, Faculdade de Ciências, and REQUIMTE, Faculdade de Ciências, Universidade do Porto, \\ Rua do Campo Alegre, 687, 4169-007 Porto, Portugal
}

Received: October 3, 2007; In Final Form: November 8, 2007

\begin{abstract}
In this work we report on the remarkable voltammetric features of graphite electrodes, which were modified with mercaptoundecanoic acid derivatized gold nanoparticles (Au-MUA NPs) by simple adsorption from basic aqueous solution. Atomic force microscopy measurements proved a fairly uniform adsorption of the nanoparticles in the form of clusters, and consecutive island formation. The electrochemical features of the modified electrodes were probed by cyclic voltammetry, while using various redox probes in several different setups. The catalytic effects of the adsorbed clusters on the graphite electrodes proved to be highly reproducible, time dependent, and of nonselective nature. The main advantages of the proposed methodology are seen by the simplicity of the modification procedure, the stability of the self-assembled gold nanoparticle film, their applicability in various voltammetric scenarios, and the potential employment of the Au-MUA NP modified electrodes as sensors for various systems.
\end{abstract}

\section{Introduction}

In the family of solid electrodes, graphite is probably the most extensively exploited in various electroanalytical studies. ${ }^{1-4}$ Graphite, in many respects, is a very suitable electrode for various electrochemical purposes. Its attractive features include access to wide cathodic and anodic potential ranges, low electrical resistance and residual currents, and a reproducible surface structure that can be easily cleaned. It shows wide thermal stability and morphological diversity, existing in a variety of forms suitable for diverse electrochemical applications, such as carbon fibers, glassy carbon, graphite pastes and composites, and many more. ${ }^{1}$ It is worth noting that in the past couple of years, edge plane pyrolytic graphite electrodes have emerged as a material showing superb features over other types of graphite electrodes [see ref 5]. The graphite surface is equally suitable for electrochemical analysis of both lipophilic and hydrophilic compounds, ${ }^{1,3-6}$ and these electrodes have been explored as biological sensors in various studies [see ref 1 , for example]. The surface of graphite electrodes can be modified in a number of ways in order to improve their performances in various electrochemical systems. Protein-film voltammetry, ${ }^{7,8}$ abrasive-stripping voltammetry, ${ }^{3}$ thin-film and three-phase voltammetry, ${ }^{4,9}$ and nanoparticle modified graphite surfaces ${ }^{10,11}$ are just a few of the recent important applications of modified graphite electrodes. In the past few years, modification of solid electrodes with nanoparticles has attracted considerable interest. The nanoparticle-modified electrodes often display unusual physical and catalytic properties, finding huge applicability in

* To whom correspondence should be addressed: E-mail cmpereir@ fc.up.pt. E-mail: rgulaboski@fc.up.pt.

CIQ-UP L4.

$\doteqdot$ REQUIMTE

$\S$ On leave from the Department of Chemistry, Faculty of Natural Sciences and Mathematics, "Ss. Kiril i Metodij University" Skopje, Macedonia, and Faculty for Management of Environment, FON University, Skopje, Macedonia. the fields of biosensors, medicine, pharmacy, electrocatalysis, and so on. ${ }^{10,11}$ From this point of view, the modification of the graphite electrodes with various nanostructures also represents an important research field. ${ }^{12-16}$ In the family of the nanostructures, gold nanoparticles (Au NPs) are especially attractive due to their relatively easy synthesis in various shapes and sizes, their long-term stability, and their unique physicochemical properties. ${ }^{12-20} \mathrm{Au}$ NPs can be used for modifying various metallic and nonmetallic surfaces, while showing impressive catalytic features. In this paper, we present a simple method for modifying graphite electrodes with gold nanoparticles that are stabilized with mercaptoundecanoic acid (Au-MUA NPs). The spontaneous assembly of Au-MUA NPs from basic aqueous solution onto a bare graphite electrode has generated chemically and electrochemically stable modified electrodes, which exhibit interesting catalytic features toward various redox systems compared with unmodified bare graphite. Several examples of the electrochemical utility of these Au-MUA NP modified graphite electrodes are given and discussed in this paper. The electrochemical behavior of the modified graphite electrodes confirmed the catalytic effects of the mercaptoundecanoic acid derivatized gold nanoparticles observed recently. ${ }^{21}$

\section{Experimental Section}

2.1. Chemicals. Hydrogen tetrachloroaurate(III) trihydrate $\left(\mathrm{HAuCl}_{4} \cdot 3 \mathrm{H}_{2} \mathrm{O}, 99,99 \%\right.$, Sigma Aldrich), sodium borohydride (96\%, Sigma Aldrich), methanol $\left(\mathrm{CH}_{3} \mathrm{OH}, 99.8 \%\right.$, Sigma), mercaptoundecanoic acid $\left(\mathrm{HS}\left(\mathrm{CH}_{2}\right)_{10} \mathrm{COOH}, 95 \%\right.$, Aldrich), tetraethylammonium hydroxide (40\%, aqueous solution), hydrogen peroxide $\left(\mathrm{H}_{2} \mathrm{O}_{2} 30 \%\right.$, Fluka), $\mathrm{KNO}_{3}$, (99\% purity) acetic acid, sodium acetate, $\mathrm{HNO}_{3}(69 \%$, Pronalab), potassium hexacyanoferrate(III) (p.a. quality, Merck) ferrocenium tetrafluoroborate, hexaammineruthenium(III) chloride (98\%, Aldrich), $\mathrm{HCl}$ (>37\%, Fluka), hydroazobenzene (99\% Merck), vitamin E (99.9\% Sigma-Aldrich), and DNA from calf thymus (99\%, Sigma-Aldrich) were used as received. The ionic liquid used 
in the experiments with vitamin $\mathrm{E}$ was tetraoctylammonium bis(2-ethylhexyl)sulfosuccinate (TOABEHSS), and it was synthesized according to the procedure described elsewhere. ${ }^{22}$ Millipore filtered water (resistivity $>18 \mathrm{M} \Omega \cdot \mathrm{cm}$ ) was used to prepare all aqueous solutions and for rinsing. Before use, all the glassware was cleaned with freshly prepared aqua regia $\left(\mathrm{HNO}_{3}\right.$ : $\mathrm{HCl}=1: 3, \% \mathrm{v} / \mathrm{v})$, rinsed abundantly with Millipore water, and dried.

2.2. Synthesis of Mercaptoundecanoic Acid Stabilized Au NPs. Gold clusters of $3.0 \mathrm{~nm}$ average diameter were synthesized as described in ref 21 . Briefly, $0.5 \mathrm{mmol}$ of $\mathrm{HAuCl}_{4}$ dissolved as $8 \%$ methanolic solution was mixed under vigorous stirring with $1.0 \mathrm{mmol} / \mathrm{L}$ mercaptoundecanoic acid previously dissolved in $100 \mathrm{~mL}$ of methanol, in an $500 \mathrm{~mL}$ Erlenmeyer flask. Successively, $25 \mathrm{~mL}$ of freshly prepared $\mathrm{NaBH}_{4}(0.2 \mathrm{~mol} / \mathrm{L})$ was added dropwise under strong stirring. The formation of the gold clusters was confirmed by the progressive appearance of a brown precipitate during $2 \mathrm{~h}$ of reaction. The Au-MUA NPs obtained were purified by repeated sonication and centrifugation in pure methanol and successively $50 \%(\mathrm{v} / \mathrm{v})$ water/methanol (200 mL). The precipitate obtained was filtered on precut membranes and dried at room temperature in a desiccator for about $24 \mathrm{~h}$.

2.3. Transmission Electron Microscopy (TEM). The TEM images were recorded using a Tecnai G2 microscope operating at $120 \mathrm{kV}$ with a point resolution of $0.5 \mathrm{~nm}$. A drop of diluted TEAOH aqueous solution of Au-MUA NPs was deposited on Formvar copper-carbon grids, allowed to dry at least $24 \mathrm{~h}$, and imaged. The size distribution of the NPs was estimated using free software, Image J.

2.4. UV-Vis Spectroscopy. The UV-vis spectra of the samples were recorded on a Hitachi U-3000 spectrophotometer in the range $200-800 \mathrm{~nm}$, using quartz cuvettes with $1 \mathrm{~cm}$ light path and Au-MUA NP solution of $0.10 \mathrm{mg} / \mathrm{mL}$ in TEAOH aqueous solution $(0.005 \%, \mathrm{v} / \mathrm{v})$.

2.5. Graphite Electrode Preparation. A graphite rod ("black graphite", product of Graf Tech, UCAR SNC, La Lechere, France) with a diameter of $0.30 \mathrm{~cm}$ was used as a working electrode. Before every new experiment, the graphite was abraded with SiC paper (600), sonicated for 30-40 s in water, rinsed with pure water and acetone, and dried in air. The modification of the surface of the graphite with negatively charged, long-chain thiol capped Au nanoparticles (Au-MUA NPs) was performed by simple immersion of the electrode in the $0.14 \mathrm{mg} / \mathrm{mL}$ gold clusters dissolved in diluted tetraethylammonium hydroxide (TEAOH) aqueous solution $(0.005 \%$ $\mathrm{v} / \mathrm{v})$. Different times of adsorption were tested, as will be explained further.

2.6. Cyclic Voltammetry. Cyclic voltammograms were recorded with the EG\&G PAR 273 potentiostat, by using a three-electrode cell with a graphite electrode as a working electrode, an $\mathrm{Ag} / \mathrm{AgCl}$ (saturated $\mathrm{KCl}$ ) electrode as a reference electrode, and a platinum wire as an auxiliary electrode. In the thin-film-electrode experiments, with vitamin $\mathrm{E}$ dissolved in ionic liquid, a droplet of that solution $(0.5 \mu \mathrm{L})$ was deposited on the bare graphite electrode with the help of a micropipet; the graphite-modified electrode was thereafter immersed into aqueous solutions of different $\mathrm{pH}$ values. The electrochemical cell was enclosed in a grounded Faraday cage, and the measurements were performed at room temperature $\left(25^{\circ} \mathrm{C}\right)$.

2.7. Atomic Force Microscopy. AFM images were recorded using a Molecular Imaging, PicoLe atomic force microscope. The surface topography was measured using a silicon cantilever/ tip (Nanosensors) with a resonance frequency between 115 and
$450 \mathrm{kHz}$. A freshly cleaned piece of bare carbon electrode was fixed on the sample plate of the microscope and imaged; successively the piece was removed and washed with acetone, ethanol, and water, dried under a flow of nitrogen, and immersed for $4 \mathrm{~h}$ in diluted tetraethylammonium hydroxide (TEAOH) aqueous solution of $0.14 \mathrm{mg} / \mathrm{mL}$ mercaptoundecanoic acid derivatized gold nanoparticles. Next, the Au-MUA NP modified piece of graphite was washed with water, dried in a soft flow of nitrogen, and imaged. The images were scanned in topography (Figure 2), amplitude, and phase mode with a resolution of $512 \times 512$ pixels.

\section{Results and Discussion}

3.1. AFM Characterization of the Bare Graphite Electrode and Au-MUA Modified Carbon Electrode. The Au-MUA NPs used for the modification of the carbon graphite surface showed monodisperse sizes, an average diameter of $3.0 \mathrm{~nm}$, and a maximum absorbance peak at $525 \mathrm{~nm}$, which is consistent with previous observations $^{21}$ (see Figure 1). Figure 2 shows the topographic tapping mode AFM images recorded for the bare graphite and Au-MUA NP modified graphite electrode, respectively. The surface of bare graphite electrode proved to be organized as terraces, as found in the results based on STM measurements. ${ }^{12}$ These terraces were more easily observed on images of small sizes. For a scan size of $1.5 \times 1.5 \mu \mathrm{m}$, the root-mean-square roughness of the bare graphite was $8.5 \mathrm{~nm}$. The high affinity of the hydrocarbon chain of the MUA ligand toward the graphite surface allowed the spontaneous selfassembly of these gold clusters on the graphite electrode. As a consequence, relatively uniform distribution of the Au-MUA nanoparticles on the graphite surface in some regions and island formation in other regions were observed after $4 \mathrm{~h}$ adsorption time (see Figure 2b). The root-mean-square roughness of the graphite modified with Au-MUA NPs was $21.95 \mathrm{~nm}$ for a scan size of $7 \times 7 \mu \mathrm{m}$. The presence of the thiol determines the formation of the Au-MUA NP film as a network covering the graphite surface either uniformly or forming bigger agglomerations (metallic islands), which could explain the great improvement of the electrochemical behavior of the graphite electrode. The roughness of the Au-MUA NP modified graphite could vary on small scan sizes from 4.5 to $15.8 \mathrm{~nm}$ for a scan size of $1.5 \times 1.5 \mu \mathrm{m}$ (results not shown). Using the Gwyddion software, the total surface of the carbon electrode covered by the AuMUA NPs was estimated by the summation of the areas covered with gold nanoparticles as represented in Figure 2b, based on the topographic and amplitude (result not shown) images. The amplitude image allows distinguishing the difference between different textures of the surface. In our case, grainy features can be observed in the brightest regions in Figure $2 \mathrm{~b}$.

The total area covered by the Au-MUA NPs was $16245 \times$ $10^{-15} \mathrm{~m}^{2}$, which can be used to estimate a $33 \%$ area increase when compared with the bare carbon electrode. This is in very good agreement with the electrochemical measurements.

3.2. Electrochemical Characterization of the Au-MUA NP Modified Graphite Electrode. (a) Stability of the Thiol-Capped Au NP System. In order to test the electrochemical stability of the Au-MUA NP film, adsorption of Au-MUA NPs on graphite electrode at several prolonged accumulation times was performed, and successive cyclic voltammetry measurements were conducted (see Figure 3). The ligand used to stabilize the gold clusters (11 $\mathrm{C}$ atom aliphatic chain) has a strong adsorptive potential toward the lipophilic surface of the graphite electrode. After the modification of the graphite surface by the MUAstabilized Au NPs, the thiol is not being released when applying 

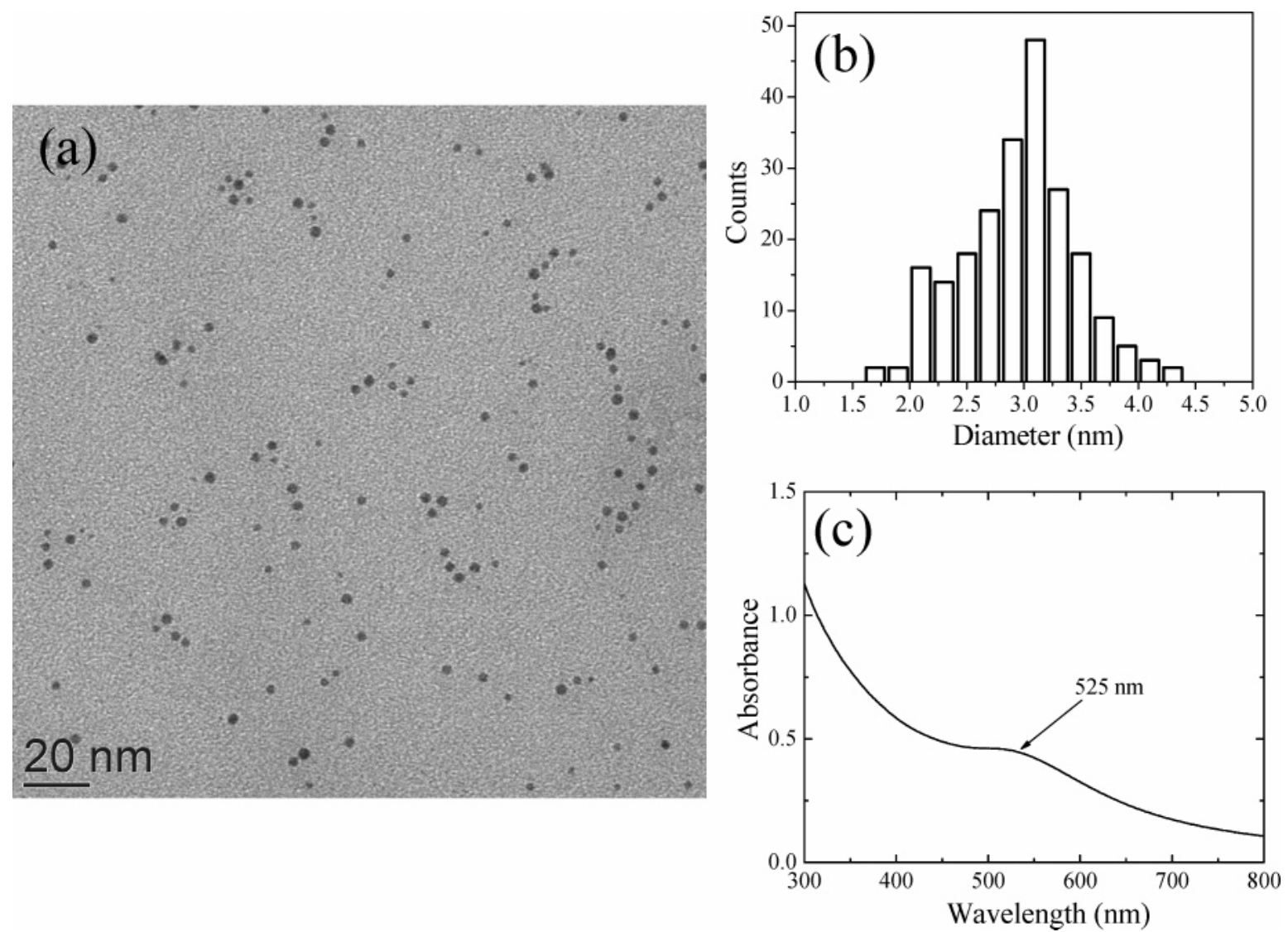

Figure 1. TEM image (a), size distribution histogram (b), and optical spectra of mercaptoundecanoic acid stabilized gold nanoparticles of 3.0 nm average diameter (c) used for the bare graphite modification represented in Figure $2 \mathrm{~b}$.

a potential difference and it keeps binding with the lipophilic alkyl chain to the graphite surface. This is proved by the features of the voltammetric measurements: no release of the dissolved Au has been observed during the consecutive application of the bias and cycling of the potential in wide range (see Figure 3). Moreover, it is well-known that the long-chain alkanes and alkylated moieties self-assemble very strongly in lamellar monolayers on a crystalline substrate like the basal plane of graphite. ${ }^{23-26}$ Rows of head groups, which may be positively or negatively charged, are separated by rows of hydrophobic alkyl chains. The chemical nature of the head groups and the length of alkyl chains define a surface potential ripple. ${ }^{23,24}$ Therefore, our finding about the stability of the long chain MUA capped Au NPs on the graphite electrode is in agreement with the literature reports. ${ }^{23-26}$ Very recently, work published by Salvarezza et al. ${ }^{12}$ has appeared, where the authors used gold nanoparticles stabilized by short and moderate alkyl chain thiols. After the spontaneous adsorption of thiol-capped Au nanoparticles on bare graphite, the authors of ref 12 observed that the thiol was released into the solution, once a potential difference was applied. Thereafter, the remaining thiol-free Au nanoparticles segregated in the nanometer-size islands on the graphite. Under anodic polarization, there were observed voltammetric peaks from the Au dissolution, as is typical for gold electrodes. ${ }^{12}$ In our case, however, the capping thiol seems to be electrochemically very stable, since no peaks of Au dissolution have been observed after applying a potential bias (see Figure 3).

(b) Voltammetric Features of Several Standard Redox Couples at the Au-MUA NP Modified Graphite Electrode. We tested the properties of the Au-MUA NP modified graphite electrode with several standard redox systems, and we compared the voltammetric features of the tested redox probes with those obtained at the unmodified bare graphite electrode. Shown in
Figure 4 are several cyclic voltammograms of ferrocenium tetrafluoroborate, recorded by using the Au-MUA NP graphite modified electrode. In these cases, the graphite electrode was immersed in TEAOH aqueous solution $(0.005 \% \mathrm{v} / \mathrm{v})$ of 0.14 $\mathrm{mg} / \mathrm{mL}$ Au-MUA NPs for different accumulation times. In comparison with the response of ferrocenium at the bare graphite electrode (curve 1 in Figure 4a), the voltammograms recorded at Au-MUA NP graphite modified electrode exhibit higher electrochemical reversibility (see curves $2-5$ in Figure $4 a$ ). This conclusion comes from the increase of the both cathodic and anodic peak currents, but also by the decreased peak-to-peak separation from $150 \mathrm{mV}$ (curve 1 in Figure $4 \mathrm{a}$ ) to $115 \mathrm{mV}$ (curve 5 in Figure 4a). Evidently, the current at the thiol-capped AuNP modified graphite electrodes significantly increases up to $4 \mathrm{~h}$ of modification. For instance, after $4 \mathrm{~h}$ of immersion in Au-MUA NP aqueous solution of the graphite electrode (curve 5 in Figure 4a), the voltammetric peak current has increased by almost an 1 order of magnitude vs the current observed at bare graphite. After prolonged immersion of the graphite electrode (more than $5 \mathrm{~h}$ ), the peak currents start to decrease dramatically (see Figure 4b). The explanation for this behavior is the occurrence of aggregation of the long-chain Au NPs, which leads to a decreasing of the active electrode surface area and blocking of the electrode surface as observed previously. ${ }^{18,21}$ Very similar effects concerning the Au-MUA NP adsorption time to the intensity of the voltammetric peaks has been observed when $\mathrm{K}_{3}\left[\mathrm{Fe}(\mathrm{CN})_{6}\right]$ was used as a redox probe (see Figure 5). In this case, it is worth mentioning that the catalytic effect of the negatively charged Au-MUA NPs toward the redox reaction of negative $\left[\mathrm{Fe}(\mathrm{CN})_{6}\right]^{3-}$ redox probe is smaller to the one observed at the positively charged ferrocenium redox probe. The peak-to-peak separation at the Au-MUA NP graphite modified electrode (curve 4 in Figure 5) decreased only for 8 

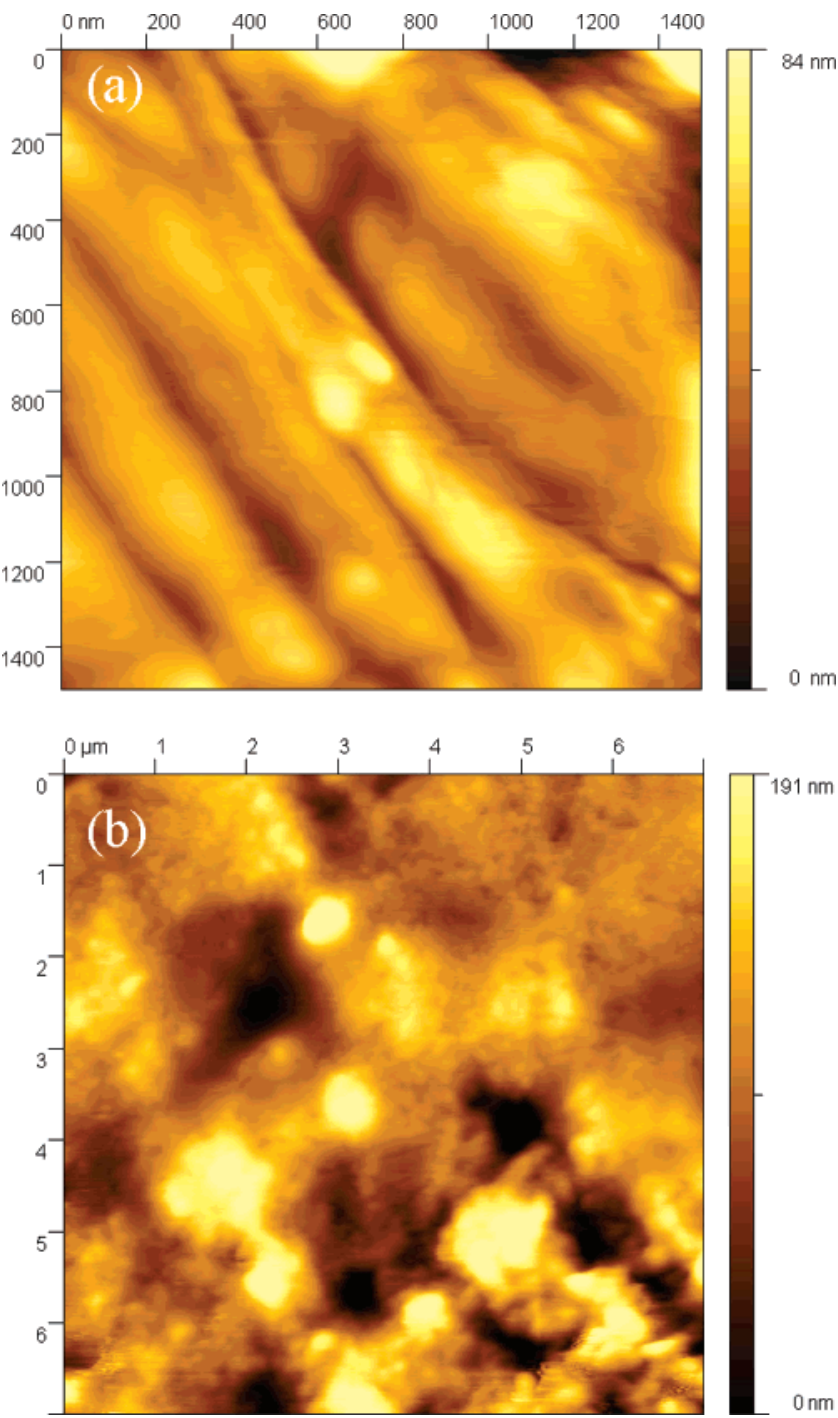

Figure 2. Topographic tapping mode AFM image of bare carbon electrode (a) and carbon electrode modified with Au-MUA NPs of 3.0 $\mathrm{nm}$ average diameter (b). Image sizes were $1.5 \times 1.5 \mu \mathrm{m}$ (a) and $7 \times$ $7 \mu \mathrm{m}$ (b), respectively.

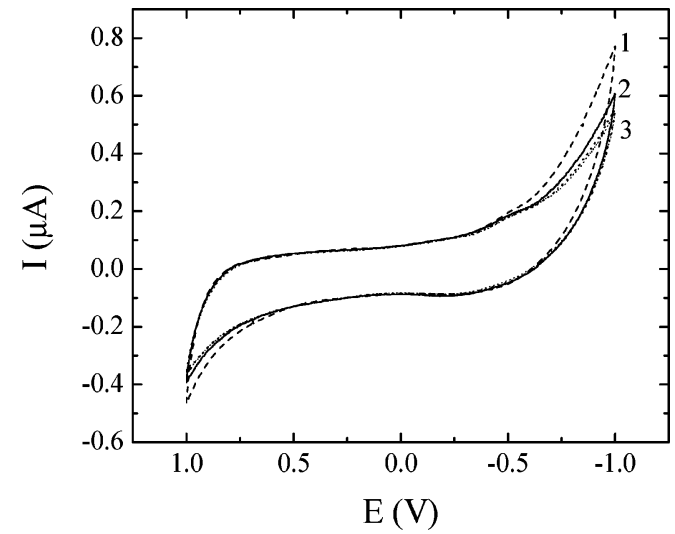

Figure 3. Cyclic voltammograms representing the stability of the AuMUA NP film assembled on graphite electrode. (1) Represents the bare graphite, (2) represents the Au-MUA NP modified graphite after $2 \mathrm{~h}$ of immersion in Au-MUA NP solution, and (3) represents the consecutive cycling after $4 \mathrm{~h}$ of immersion. The supporting electrolyte used was $0.1 \mathrm{~mol} / \mathrm{L} \mathrm{KNO}_{3}$. Scan rate was $50 \mathrm{mV} / \mathrm{s}$.

$\mathrm{mV}$ vs that recorded at the bare graphite electrode (curve 1 in Figure 5), while the maximal current increase in the case of $\mathrm{K}_{3}\left[\mathrm{Fe}(\mathrm{CN})_{6}\right]$ redox probe was about $40 \%$ compared to the current observed at bare graphite. It is worth mentioning that we also tested the catalytic features of Au-MUA NP modified graphite to the electron transfers of hydroazobenzene in acidic media $(\mathrm{pH} 3.0)$ and $\left[\mathrm{Ru}\left(\mathrm{NH}_{2}\right)_{6}\right] \mathrm{Cl}_{3}$ in neutral media. In both cases, an increase of the voltammetric responses of about $30 \%$ has been observed (after $4 \mathrm{~h}$ adsorption time) compared to their responses at bare graphite electrodes (figures not shown). These results confirmed the optimum time for the Au-MUA NP adsorption on the electrode surface, which was $4 \mathrm{~h}$ as previously observed, ${ }^{21}$ although the self-assembly of the same gold clusters in ref 21 was based on electrostatic interaction and at a different electrode surface (gold).

(c) Effect of Au-MUA NP Self-Assembly on the Electron Transfer of Vitamin E Dissolved in Lipophilic Ionic Liquid. Thin-film voltammetry is a recent electrochemical technique, developed for studying the processes of electron and ion transfer across the interface of two immiscible solvents [see refs 2731 , for example]. We have studied the thin-film system using vitamin $\mathrm{E}$ (lipophilic quinone-like compound) dissolved in lipophilic ionic liquid (TOABEHSS), in order to test the catalytic features of the investigated Au-MUA NPs assembled on a graphite electrode. An extensive study of the redox features of pure vitamin $\mathrm{E}$ in a droplet-modified electrode setup can be found elsewhere. ${ }^{32}$ Figure 6 a shows the voltammetric behavior of the thin-film graphite electrode, modified with an ionic liquid containing vitamin $\mathrm{E}$. The modification of the graphite electrode was performed by spreading a drop of TOABEHSS ionic liquid solution, containing dissolved vitamin $\mathrm{E}$, onto the surface of bare graphite electrode, which was subsequently immersed in aqueous solutions having various $\mathrm{pH}$ values. Like most of the quinones, vitamin $\mathrm{E}$ undergoes two-electron redox transformation, which is coupled by exchange of two $\mathrm{H}^{+}$across the waterionic liquid interface. The huge irreversibility of the voltammetric responses of vitamin $\mathrm{E}$, depicted in peak-to-peak separations higher than $500 \mathrm{mV}$, is the main feature of the voltammograms represented in Figure 6a. This irreversibility is due to the slow electron transfer between the graphite electrode and vitamin E redox probe, ${ }^{32}$ but is also due to the hindered $\mathrm{H}^{+}$transfer across the water-lipophilic ionic liquid interface. ${ }^{33}$ The ionic liquid used in these experiments is highly lipophilic, and its hydrophobicity is a main cause for the slowness in establishing equilibrium by the protonation process, after the redox transformation of vitamin E. The support for the last statement can be also found in the conditional existence of voltammetric response of vitamin $\mathrm{E}$ in this setup; there are adequately defined voltammograms only when thin-film electrode is immersed in highly proton-concentrated media (see Figure 6a). However, the features of the voltammetric response of vitamin E change dramatically, when the thin film of ionic liquid solution containing vitamin $\mathrm{E}$ is spread over the thiolcapped Au NP modified graphite electrode (see Figure 6b). In this case, besides the increase of the voltammetric current by over 1.5 orders of magnitude, the potential separation between the cathodic and anodic peaks decreases from $600 \mathrm{mV}$ to about $250 \mathrm{mV}$ (curve 5 in Figure 6b), while the system exhibits quasireversible features. It is worth stressing that the peak observed under cathodic polarization at potentials about +0.25 $\mathrm{V}$ at curve 5 in Figure $6 \mathrm{~b}$ is somewhat atypical for this system, and can be easily misinterpreted and considered as a part of the background current. However, from the blank cyclic voltammogram of the ionic liquid presented in Figure 6b, we can see that there is no such feature in that potential region. Moreover, we also performed experiments while running the potential up to $-1.00 \mathrm{~V}$, and we could not see other obvious 

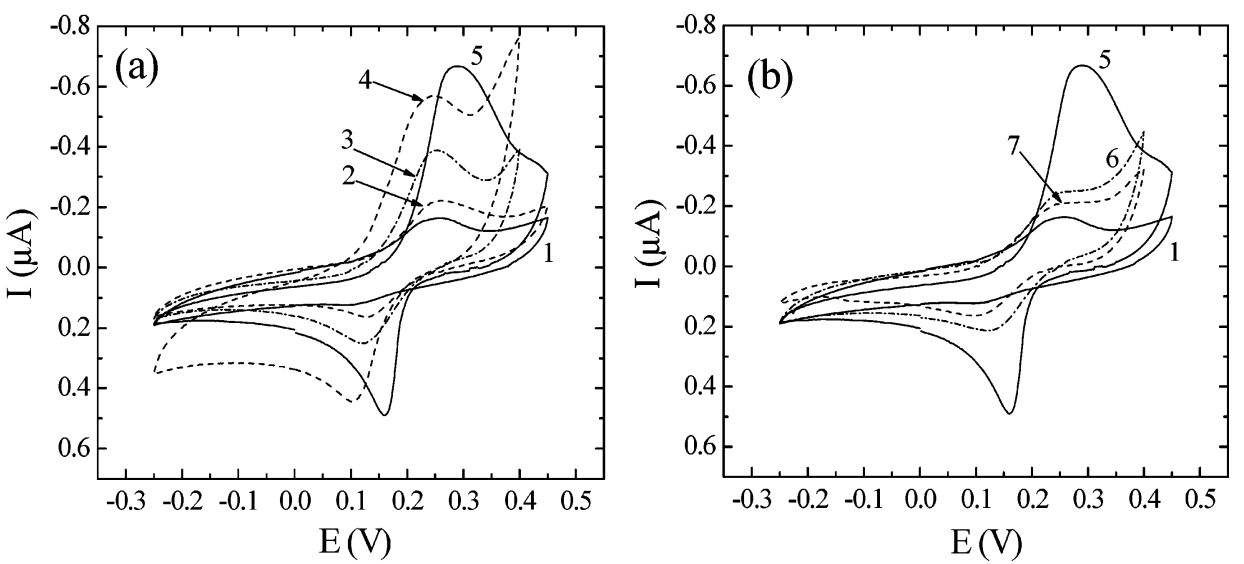

Figure 4. Cyclic voltammograms showing the effects of the modification time of the graphite electrode with negatively charged Au-MUA NPs. (a) Curve 1, bare graphite electrode; curve 2, $45 \mathrm{~min}$; curve 3, $2 \mathrm{~h}$; curve 4, $3 \mathrm{~h}$; and curve 5, $4 \mathrm{~h}$ of immersion, respectively. (b) Curve 6, $5.5 \mathrm{~h}$, and curve $7,15 \mathrm{~h}$ of immersion. Redox probe used was ferrocenium tetrafluoroborate. $c$ (ferrocenium ${ }^{+}$) $=0.1 \mathrm{mmol} / \mathrm{L}$; Supporting electrolyte was $0.1 \mathrm{~mol} / \mathrm{L} \mathrm{KNO}_{3}$. Scan rate was $50 \mathrm{mV} / \mathrm{s}$.

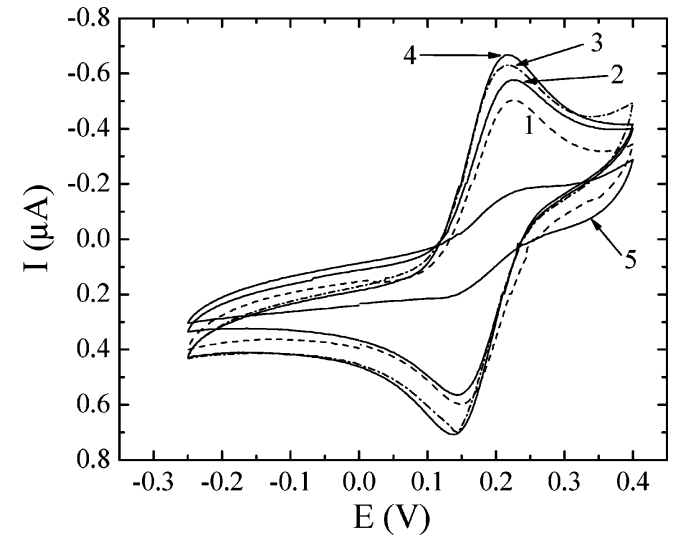

Figure 5. Cyclic voltammograms showing the effects of the modification time of the graphite electrode with negatively charged Au-MUA NPs. Redox probe used was $\mathrm{K}_{3}\left[\mathrm{Fe}(\mathrm{CN})_{6}\right]$, with $c\left(\left[\mathrm{Fe}(\mathrm{CN})_{6}\right]^{3-}\right)=0.1$ $\mathrm{mmol} / \mathrm{L}$. Modification time: curve 1, bare graphite electrode; curve 2, $30 \mathrm{~min}$; curve 3, $75 \mathrm{~min}$; curve $4,4 \mathrm{~h}$; curve 5, $12 \mathrm{~h}$. Supporting electrolyte was $0.1 \mathrm{~mol} / \mathrm{L} \mathrm{KNO}_{3}$. Scan rate was $50 \mathrm{mV} / \mathrm{s}$.

electrochemical activity in that region (not shown). These facts enable us to believe that the feature of the cyclic voltammogram observed at $+0.25 \mathrm{~V}$ under cathodic polarization (curve 5, Figure 6b) is due to the electrochemical activity of vitamin E. Obviously, the Au-MUA NPs are significantly lowering the barrier for electron transfer between the electrode and vitamin $\mathrm{E}$, which results in an increase of the reversibility of the entire coupled electron/ion transfer process.

(d) Effect of the Au-MUA NPs on the Redox Systems Coupled by Regeneration Reaction (ECat Reactions). The redox reactions coupled by consecutive regeneration reactions (known also as ECat or $\mathrm{EC}^{\prime}$ reactions) are of great importance for designing sensors for various biological systems. ${ }^{34-36}$ Usually, these systems are described by the following reaction schemes:

$$
\begin{aligned}
& \mathrm{Ox}+n \mathrm{e}^{-} \leftrightarrow \mathrm{Red} \\
& \mathrm{Red}+\mathrm{Cat} \rightarrow \mathrm{Ox}
\end{aligned}
$$

In this scheme, "Ox" is the symbol for the oxidized form of the redox probe, initially present in the system, and "Red" is its reduced form. After Ox is reduced to Red, this reduced form can be reoxidized to the initial form, Ox, in the presence of an appropriate oxidizing agent (catalyst), Cat. The voltammetric features of such systems are well-known in the literature, ${ }^{34-37}$ and have been widely explored. In our case, we used $\mathrm{K}_{3}[\mathrm{Fe}-$
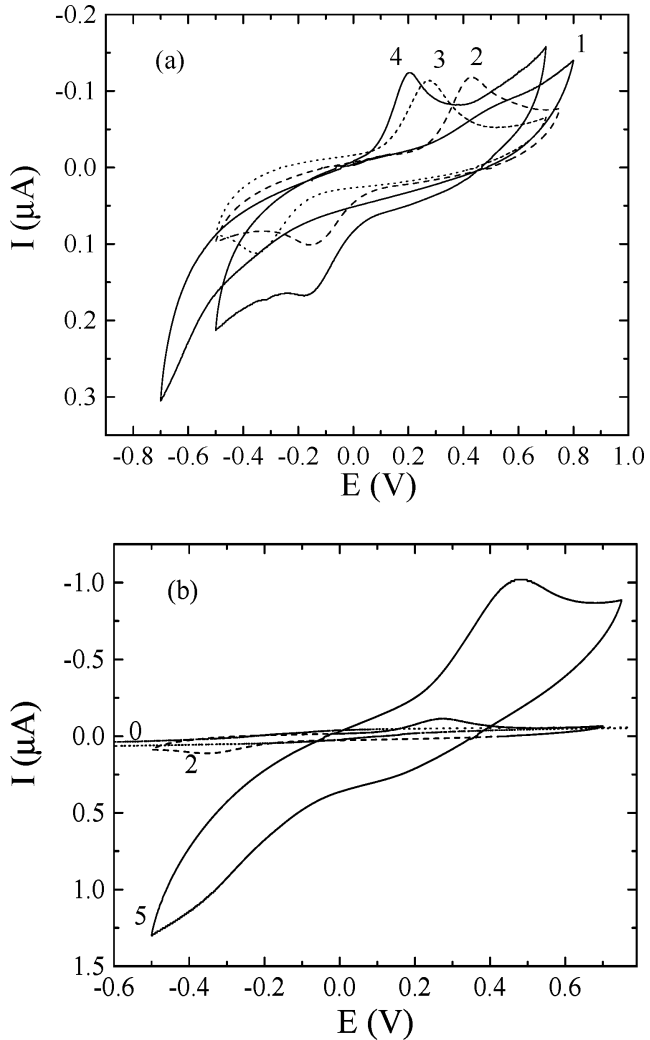

Figure 6. (a) Thin-film-electrode experiments of graphite electrode modified with vitamin E dissolved in TOABEHSS ionic liquid, and spread on its surface. The modified electrode was immersed in aqueous solutions having $\mathrm{pH} 3$ (curve 1), $\mathrm{pH} 1$ (curve 2), $2 \mathrm{~mol} / \mathrm{L}$ nitric acid (curve 3), and $5 \mathrm{~mol} / \mathrm{L}$ nitric acid (curve 4 ). (b) Curve 5 was recorded when ionic liquid film of vitamin E solution was spread on Au-MUA NP modified graphite electrode (adsorption time of $4 \mathrm{~h}$ ), and immersed in $\mathrm{pH} 1.0$ aqueous solution. Curve 0 represents the blank of the thin film of the ionic liquid at the graphite electrode (without vitamin E) immersed in $\mathrm{pH} 1.0$ aqueous solution. Scan rate was $50 \mathrm{mV} / \mathrm{s}$.

$\left.(\mathrm{CN})_{6}\right]$ as a redox probe, and we studied the features of its regenerative reaction by hydrogen peroxide at bare and $\mathrm{Au}$ MUA NP modified graphite electrodes. Shown in Figure 7a are several cyclic voltammograms of $\mathrm{K}_{3}\left[\mathrm{Fe}(\mathrm{CN})_{6}\right]$ in the presence of various concentrations of hydrogen peroxide, recorded by using an unmodified bare graphite electrode. From the cyclic voltammograms in Figure 7a, one can see that the regenerative effect in this case is very small. By contrast, at the modified Au-MUA NP graphite electrode (Figure 7b), the regenerative 

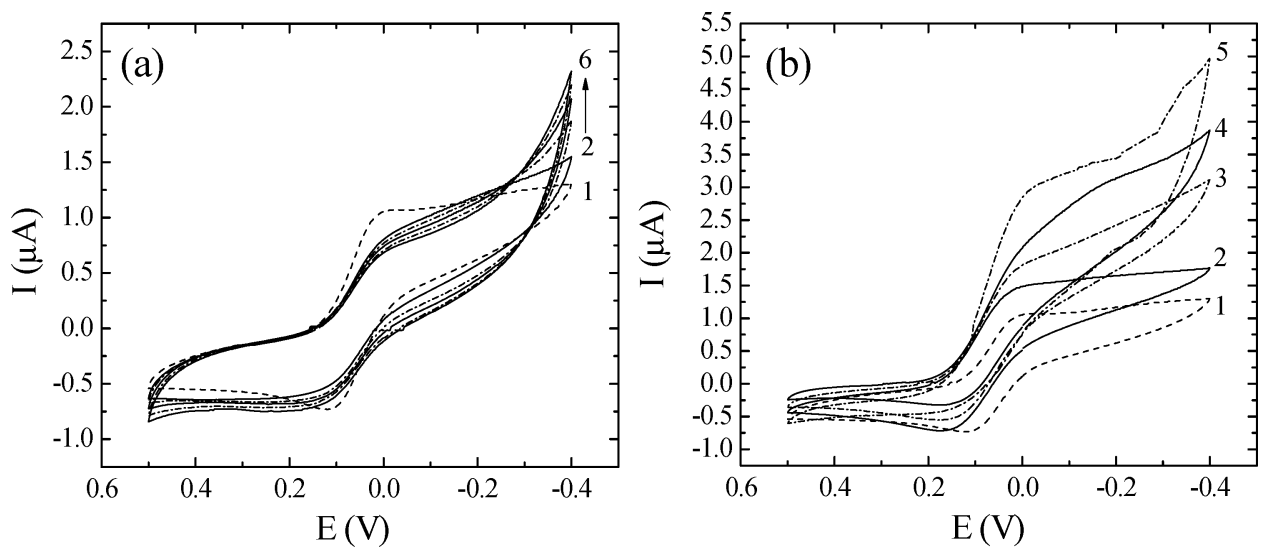

Figure 7. (a) Cyclic voltammograms showing the effect of hydrogen peroxide by the regeneration reaction of $\mathrm{K}_{3}\left[\mathrm{Fe}(\mathrm{CN})_{6}\right]$ at the bare graphite electrode. $c\left(\left[\mathrm{Fe}(\mathrm{CN})_{6}\right]^{3-}\right)=0.25 \mathrm{mmol} / \mathrm{L} ; c\left(\mathrm{H}_{2} \mathrm{O}_{2}\right) / \mathrm{mmol} \mathrm{L}^{-1}=0$ (1), 0.1 (2), 0.2 (3), 0.3 (4), 0.4 (5), and 0.5 (6). (b) Cyclic voltammograms recorded at Au-MUA NP modified graphite electrode (adsorption time of $4 \mathrm{~h}$ ): $c\left(\mathrm{H}_{2} \mathrm{O}_{2}\right) / \mathrm{mmol} \mathrm{L}^{-1}=0$ (1), 0.1 (2), 0.2 (3), 0.3 (4), and 0.4 (5). The scan rate was $50 \mathrm{mV} / \mathrm{s}$, while the supporting electrolyte was $0.1 \mathrm{~mol} / \mathrm{L}$ acetate buffer $(\mathrm{pH} 4.70)$.
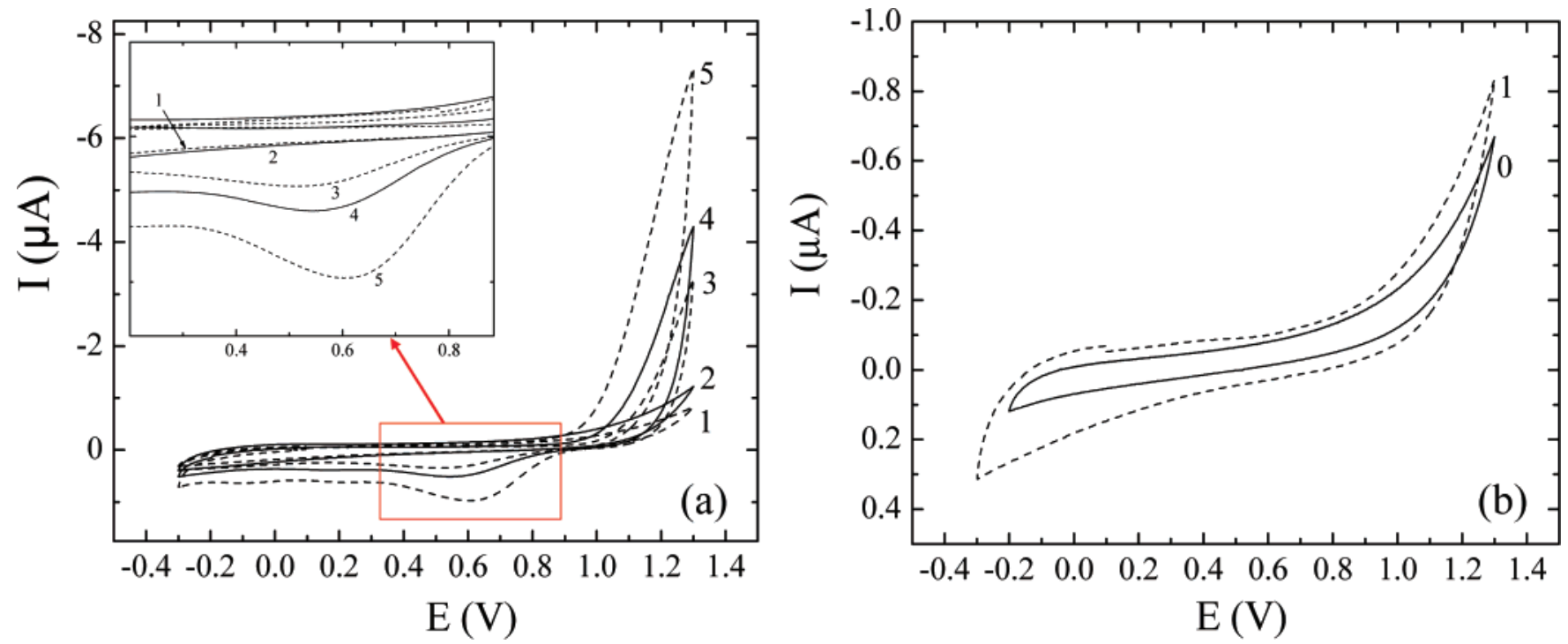

Figure 8. (a) Cyclic voltammogram recorded at bare graphite electrode immersed in $0.1 \mathrm{mg} / \mathrm{mL}$ DNA solution (pH 1.0 , accumulation time of 30 min) (curve 1). Curve 2 is a cyclic voltammogram of Au-MUA NP modified graphite electrode (4 h of modification) immersed in DNA-free solution ( $\mathrm{pH}$ 1.0). Curves 3, 4, and 5 are cyclic voltammograms obtained at Au-MUA NP modified graphite electrode in pH 1.00, recorded after the modified electrode was previously immersed for 1,2 , and $5 \mathrm{~h}$ in DNA solution under closed circuit, respectively. (b) Curve 0 represents the cyclic voltammogram recorded at bare graphite electrode immersed in supporting electrolyte $\left(\mathrm{HNO}_{3}\right)$ after $1 \mathrm{~h}$ of accumulation; curve 1 is the same as in (a). Scan rate was $30 \mathrm{mV} / \mathrm{s}$. Accumulation potential was $0.7 \mathrm{~V}$.

reaction of the reduced form of $\mathrm{K}_{3}\left[\mathrm{Fe}(\mathrm{CN})_{6}\right]$ by hydrogen peroxide is easily feasible, giving rise to the development of cyclic voltammograms that are common for this kind of reaction. ${ }^{34-37}$ An increase of the hydrogen peroxide concentration in the electrochemical cell is followed by the decrease of the anodic peak and the increase of the cathodic peak of the studied redox probe (see Figure 7b). Moreover, the upraised currents at the end of the cathodic potential limit are additional typical features for this particular mechanism. ${ }^{35-37}$ Linear dependence between the cathodic peak currents and the peroxide concentration exists in a wide micromolar region. These simple experiments show that the surface of a thiol-capped Au NP graphite electrode is (i) a superior tool for monitoring the hydrogen peroxide concentration, and (ii) it is a more adequate environment for studying the regenerative redox reactions, in general, when compared with the bare graphite.

(e) Exploring the Au-MUA NP Modified Graphite Electrode for Direct Detection of DNA. The majority of the electrochemical sensors for DNA determination are based on indirect measurement of the DNA activity to the electron-transfer reactions of some standard redox mediators such as methylene blue, ${ }^{38}$ phenanthroline, ${ }^{39,40}$ or bipyridine metal complexes. ${ }^{41}$ Although several electrochemical methods for direct determinations of DNA at graphite electrodes are also reported, ${ }^{42}$ all these involve some kind of pretreatment of DNA (i.e., chemical denaturation or thermal decomposition). Very often, irreproducible results are obtained, which are mainly caused by the complex chemical and physical features of DNA. ${ }^{43}$ Several excellent reviews of electrochemical DNA sensors can be found elsewhere. ${ }^{44-46}$ Our attempts to observe faradaic electrochemical activity of DNA at our bare graphite electrode (in buffers with $\mathrm{pH}$ 1.00-7.00) have failed in all cases, even after chemical and thermal decomposition of DNA. However, by using the AuMUA NP modified graphite electrode, we succeed in observing a voltammetric signal of DNA. For this purpose, the modified Au-MUA NP graphite electrode was immersed in DNA solutions ( $\mathrm{pH}$ 4.70) for certain times under a closed circuit (accumulation potential of $0.70 \mathrm{~V}$ ). Subsequently, the electrode was removed from the DNA solutions, and used for voltammetric measurements, immersed in DNA-free buffer of $\mathrm{pH} 1.00$. An electrochemical activity of DNA was observed starting at $+0.52 \mathrm{~V}$ (see Figure 8, curve 3), progressively shifted toward 
more positive potentials $(+0.55 \mathrm{~V}$, curve 4 , and $+0.60 \mathrm{~V}$, curve 5 , in Figure 8 ). The voltammetric peak increased proportionally to the accumulation time and DNA concentration. It is worth mentioning that the electrochemical activity of DNA in this setup has been observed only in highly acidic media. All other attempts to find electrochemical activity of DNA in other media failed.

\section{Conclusions}

In this work, graphite electrodes have been modified with mercaptoundecanoic acid stabilized gold nanoparticles (AuMUA NPs) of $3.0 \mathrm{~nm}$ average diameter by simple adsorption of the clusters from basic aqueous solution. The electrochemical features of the Au-MUA NP modified graphite electrodes were probed with several redox systems. It has been observed that the Au-MUA NPs significantly improve the electrochemical properties of the bare graphite electrode, which is portrayed in the enhanced feasibility of electron transfers by all studied redox systems. Contrary to the electrostatic anchoring of similar nanoparticles at the charged sites of the protein-modified surfaces of gold electrodes, ${ }^{21}$ the mechanism of self-assembling of the Au-MUA NPs at bare graphite electrodes should be quite different. In principle, the adsorption of the Au-MUA NPs at the lipophilic surface of the graphite will take place via the lipophilic alkyl chain of the ligand (mercaptoundecanoic acid). ${ }^{23-26}$ In this way, the hydrophilic gold sites of the AuMUA NPs will be oriented toward the water solution. Very likely, this specific orientation of the Au-MUA NPs contributes to better electron conductivity with respect to the bare graphite. Moreover, this type of self-assembling will be portrayed by a high-effective surface area of the gold clusters, which will result in significantly enhanced mass-transfer properties of the studied redox systems. At this stage, it is worth stressing that both these effects of the Au-MUA NPs, i.e., increased effective surface area and increased conductivity of the modified graphite electrodes, will contribute to getting higher voltammetric currents by the studied redox systems. However, the effect of an increased conductivity will be additionally portrayed in the decrease of the peak-to-peak separations of the cyclic voltammograms of the studied redox probes. Consequently, knowing this fact, and knowing the percentage of increase of the surface area from the AFM experiments, we could estimate the relative increase of the values of the standard constant of electron transfer for the studied redox systems obtained at Au-MUA NP graphite electrodes (modified for $4 \mathrm{~h}$ ) vs the same values obtained at bare graphite electrodes. This has been done by fitting the features of the experimentally obtained cyclic voltammograms (i.e., the peak-to-peak separations and the relative increase of the cathodic and anodic peak currents) with those obtained from the computational simulations by considering the semi-infinite planar diffusion model. ${ }^{47}$ In this way, we calculated that the relative rise of the value of the standard rate constants $\left(k_{\mathrm{s}}\right)$ of electron transfers of vitamin E, ferrocenium ${ }^{+}$, and [hexacyanoferrate $]^{3-14-}$ redox probes at Au-MUA NP modified graphite was $10^{1.12}, 10^{0.54}$, and $10^{0.20}$ orders of magnitude higher when compared with the values obtained at the bare graphite electrode, respectively. Indeed, the differing increase of the values of $k_{\mathrm{s}}$ is mainly due to the different natures (electronic structures) of the redox couples studied, and their changed affinities toward the modified electrode material. By exploring the value of the increased effective surface electrode area estimated from the AFM experiments (33.2\%, if we assume homogeneous adsorption at the graphite electrode), we can say that the enhanced mass transfer at the Au-MUA NP modified graphite electrode would roughly give about $33 \%$ contribution to the rise of the peak currents. This would mean that in the case of the [hexacyanoferrate] ${ }^{3-/ 4-}$ redox couple the majority of the peak current increase is due to the effect of the increased surface area. Quite opposite, for ferrocenium ${ }^{+}$and vitamin E redox couples the dominating effect in the increase of the peak currents is seen by an increased value of the standard rate constant of electron transfer $\left(k_{\mathrm{s}}\right)$ at the Au-MUA NP modified graphite electrode. With the estimated parameters of the surface electrode coverage from the AFM experiments, and with the voltammetrically calculated values of the increased standard rate constant of electron transfer at the Au-MUA NP modified graphite electrode, we got very good fitting between the simulated voltammograms and the experimental ones. The good fitting between the experimental and theoretical voltammograms could serve as an additional supporting indicator for the discussed phenomena.

In general, the Au-MUA nanoclusters seem to be very suitable for modifying both metallic and nonmetallic electrodes. The main advantages of the reported methodology are portrayed in (i) the simplicity in the preparation of the Au-MUA NPs, (ii) the simplicity of modification of the graphite electrode with these particular gold clusters, (iii) the very fast and easy cleaning of the modified graphite electrode, (iv) the possibility for catalyzing the electron transfers by different redox systems, and (v) the possibility for using the Au-MUA NP modified graphite electrode as a sensor for various important biomolecules. These nanostructures could have a wide range of applications in sensing and electronic device construction. The further investigation of this methodology will be focused on analyzing the electrochemical features of various systems as functions of the size and structure of these nanoparticles. Also, a challenging task will be to study the effect of the thiol-capped Au NPs not only on the electron-transfer barriers, but also on the ion-transfer kinetics. For this, experiments performed with thin-film and three-phase electrodes, along with the classical four-electrode voltammetry, will be considered in our lab in the near future. Indeed, in further studies on this topic, there will be space not only for AFM and voltammetric techniques, but also for extensive use of electrochemical impedance studies.

Acknowledgment. R.G. thanks the Fundação para a Ciência e a Tecnologia (FCT) of Portugal for providing a postdoctoral fellowship (SFRH/1489/2004), M.C. acknowledges financial support from UE project IONMET (Contract no. IP 5157432), and C.M.P. acknowledges support from FCT (POCI/QUI/ 57679/2004).

\section{References and Notes}

(1) Gilmartin, M. A. T.; Hart, J. P. Analyst 1995, 120, 1029-1045.

(2) Martorell, D.; Cespedes, F.; Martinez-Fabregas, E.; Alegret, E. Anal. Chim. Acta 1994, 290, 343-348.

(3) Scholz, F.; Meyer, B. In Voltammetry of Solid Microparticles Immobilized on Electrode Surfaces, Bard. A. J., Rubinstein, I., Eds.; Marcel Dekker: New York, 1998; Vol. 20.

(4) Scholz, F.; Schröder, U.; Gulaboski, R. Electrochemistry of Immobilized Particles and Droplets; Springer: Heidelberg, Berlin, 2005.

(5) Banks, C. E.; Compton, R. G. Anal. Sci. 2005, 21, 1263-1268.

(6) Welch, C. M.; Banks, C. E.; Simm, A. O.; Compton, R. G. Anal. Bioanal. Chem. 2005, 382, 12-21.

(7) Armstrong, F. A.; Heering, H. A.; Hirst, J. Chem. Soc. Rev. 1997, $26,169-179$.

(8) Armstrong, F. A. Russ. J. Electrochem. 2002, 38, 49-62.

(9) Scholz, F.; Gulaboski, R. ChemPhysChem 2005, 6, 16-28.

(10) Welch, C. M.; Compton, R. G. Anal. Bioanal. Chem. 2006, 384, $601-619$.

(11) Hernandez-Santos, D.; Gonzales-Garcia, M. B.; Garcia, A. C. Electroanalysis 2002, 14, 1225-1235. 
(12) Grumelli, D.; Vericat, C.; Benitez, G.; Vela, M. E.; Salvarezza, R. C.; Giovanetti, L. J.; Ramallo-Lopez, J. M.; Requejo, F. G.; Craievich, A. F.; Shon, Y. S. J. Phys. Chem. C 2007, 111, 7179-7184.

(13) Takele, H.; Scürmann, U.; Greve, H.; Partekar, D.; Zaporojtchenko,

V.; Faupel, F. Eur. Phys. J.: Appl. Phys. 2006, 33, 83-89.

(14) Brust, M.; Kiely, C. J. Colloids Surf., A 2002, 202, 175-186.

(15) Fullam, S.; Cottell, D.; Rensmo, H.; Fitzmaurice, D. Adv. Mater. 2000, 12, 1430-1432.

(16) Shimizu, T.; Teranishi, T.; Hasegawa, S.; Miyake, M. J. Phys. Chem. B 2003, 107, 2719-2726.

(17) Daniel, C. M.; Astruc, D. Chem. Rev. 2004, 104, 293-346.

(18) Chirea, M.; Garcia-Morales, V.; Manzares, J. A.; Pereira, C.; Gulaboski, R.; Silva, F. J. Phys. Chem. B 2005, 109, 21808-21817.

(19) Bethell, D.; Brust, M.; Schiffrin, D. J.; Kiely, C. J. Electroanal. Chem. 1996, 409, 137-143.

(20) Bastl, Z.; Franc, J.; Janda, P.; Pelouchova, H.; Samec, Z. J. Electroanal. Chem. 2007, 605, 31-40.

(21) Chirea, M.; Pereira, C. M.; Silva F. J. Phys. Chem. C 2007, 111, 9255-9266.

(22) Nishi, N.; Kawakami, T.; Shigematsu, F.; Yamamoto, M.; Kakiuchi, T. Green Chem. 2006, 8, 349-355.

(23) Rabe, J. P.; Buchholz, S. Science 1991, 253, 424-427.

(24) Rabe, J. P.; Buchholz, S. Phys. Rev. Lett. 1991, 66, 2096-2099.

(25) Yin, S.; Wang, C.; Qiu, X.; Xu, B.; Bai, C. Surf. Interface Anal. 2001, 32, 248-252.

(26) Faglioni, F.; Claypool, C. L.; Lewis, N. S.; Goddard, W. A., III. J. Phys. Chem B 1997, 101, 5996-6020.

(27) Chung, T. D.; Anson, F. C. Anal. Chem. 2001, 73, 337-342.

(28) Shi, C. N.; Anson, F. C. J. Phys. Chem. B 1998, 102, 9850-9854.

(29) Gulaboski, R.; Mirčeski, V.; Pereira, C. M.; Cordeiro, M. N. D. S.; Silva, A. F.; Quentel, F.; L’Her, M.; Lovrić, M. Langmuir 2006, 22, 3404-3412. 1949.
(31) Mirceski, V.; Gulaboski, R.; Bogeski, I.; Hoth, M. J. Phys. Chem C 2007, 111, 6068-6076.

(32) Wain, A. J.; Wadhawan, J. D.; France, R. R.; Compton, R. G. Phys. Chem. Chem. Phys. 2004, 6, 836-842.

(33) Angell, C. A.; Hu, W.; Yoshizawa, M.; Beliers, J.-P. Molten Salts. International Symposium on Ionic Liquids in Honour of Marcelle GauneEscard, France, 2003; No. 79, pp 1-12. 1333.

(35) O’Dea, J. J.; Osteryoung, J.; Osteryoung, R. A. Anal. Chem. 1981, $53,659-701$

(36) O’Dea, J. J.; Osteryoung, J. Anal. Chem. 1993, 65, 3090-3097.

(37) Mirceski, V.; Gulaboski, R. J. Solid State Electrochem. 2003, 7, $157-165$.

(38) Ozkan, D.; Kara, P.; Kerman, K.; Meric, B.; Erdem, A.; Jelen, F.; Nielsen, P. E.; Ozsos, M. Bioelectrochemistry 2002, 58, 119-126.

(39) Millan, K. M.; Mikkelsen, S. R. Anal. Chem. 1993, 65, $2317-$ 2323

(40) Erdem, A.; Meric, B.; Kerman, K.; Dalbasti, T.; Ozsoz, M. Electroanalysis 1999, 11, 1372-1376.

(41) Yang, I. V.; Ropp, P. A.; Thorp, H. H. Anal. Chem. 2002, 74, 347354

(42) Gooding, J. J. Electroanalysis 2002, 14, 205-214.

(43) Sawata, S.; Kai, E.; Ikebukuro, K.; Iida, T.; Honda, T.; Karube, I. Biosens. Bioelectron. 1999, 14, 397-404.

(44) Drummond, T. G.; Hill, M. G.; Barton, J. K. Nat. Biotechnol. 2003 , $21,1192-1199$

(45) Wang, J. Anal. Chim. Acta 2002, 288, 205-214.

(46) Kerman, K.; Kobayashi, M.; Tamiya, E. Meas. Sci. Technol. 2004 15, R1-R11.

(47) Bard, A. J.; Faulkner, L. R. Electrochemical Methods: Fundamentals and Applications; Wiley: New York, 2001. 